\title{
Bortezomib-Induced Perimyocarditis in a Multiple Myeloma Patient: A Case Report
}

\author{
Yaman Alalia Muhamed Baljevic ${ }^{b}$ \\ aDepartment of Internal Medicine, Creighton University, Omaha, NE, USA; bepartment of \\ Internal Medicine, Vanderbilt University, Nashville, TN, USA
}

\section{Keywords}

Bortezomib · Perimyocarditis · Multiple myeloma

\begin{abstract}
Bortezomib (BTZ) is a proteasome inhibitor used in the treatment of multiple myeloma (MM) and other hematological malignancies. Although carfilzomib, a second-generation proteasome inhibitor, is most strongly associated with cardiotoxicity, BTZ has been associated with several cardiovascular complications including congestive heart failure, arrhythmias, and rarely myocarditis. Here, we report the first case of a BTZ-induced perimyocarditis. The patient was a 40-year-old woman with recently diagnosed MM who was admitted to the hospital with syncope at the start of her second cycle of induction therapy with BTZ, lenalidomide, and dexamethasone. She had a witnessed syncopal event in the emergency room with the telemetry showing sustained ventricular tachycardia. Laboratory workup showed elevated $\mathrm{N}$-terminal pro B-type natriuretic peptide and normal troponin I. Transthoracic echocardiogram (TTE) showed a low ejection fraction of $40 \%$ with global hypokinesis of the left ventricle and trace pericardial effusion. Cardiac magnetic resonance imaging with gadolinium was consistent with acute myocarditis. The patient had recurrent pleuritic chest pain, and a repeat TTE showed worsening pericardial effusion consistent with pericarditis. Endomyocardial biopsy was done which showed nonspecific myocyte hypertrophy and foci of fibrosis, but was negative for giant cell myocarditis, hemochromatosis, and amyloidosis. Extensive infectious disease workup ruled out known infectious causes for perimyocarditis. Given the close timing between BTZ treatment ( 5 subcutaneous doses with a cumulative dose of $6.5 \mathrm{mg} / \mathrm{m}^{2}$ ), the absence of other iatrogenic or infectious causes, and probable or likely association with BTZ as assessed by the validated causality assessment scoring tools, it was concluded that the acute perimyocarditis was secondary to BTZ exposure. Here, we report the first case of BTZ-induced perimyocarditis and discuss the incidence and pathophysiology of BTZ-cardiovascular toxicity.
\end{abstract}

\section{Karger!}




\section{Introduction}

Bortezomib (BTZ) is a proteasome inhibitor that is currently used for the treatment of several hematologic malignancies including multiple myeloma (MM), mantle cell lymphoma, systemic light chain amyloidosis, T-cell lymphoma, Waldenstrom's macroglobulinemia/ lymphoplasmacytic lymphoma, and others [1]. Although rare, several cardiovascular complications including heart failure, ischemic heart disease, and arrythmias have been reported in association with its use [2]. Here, we report the case of a patient who developed perimyocarditis and myocardial scaring after a brief exposure to subcutaneous BTZ in the context of treatment for newly diagnosed international staging system stage I standard risk multiple myeloma.

\section{Case Report}

In February 2020, a 40-year-old woman with no prior medical history presented at the emergency department with recurrent witnessed syncopal episodes. The patient was diagnosed with MM just few months before and was just starting her second cycle of anti-MM therapy with subcutaneous BTZ, lenalidomide, and dexamethasone in 21-day cycles. BTZ was delivered at $1.3 \mathrm{mg} / \mathrm{m}^{2}$ on days $1,4,8$, and 11 . By the time of her presentation, she had received only 5 doses of BTZ (cumulative dose $6.5 \mathrm{mg} / \mathrm{m}^{2}$ ). Upon arrival at the emergency department, the patient's vital signs were stable, including heart rate, 91 beats/min; blood pressure, 138/104 $\mathrm{mm} \mathrm{Hg}$; respiratory rate, 23 breaths/min; temperature, $36.8^{\circ} \mathrm{C}$; and oxygen saturation, $91 \%$ on room air. She reported 2 -week history or gradually worsening exertional dyspnea and a 15-pound weight gain. She was evaluated as an outpatient with a computed tomography of the chest that showed evidence of bronchitis but no evidence of pulmonary emboli. While in the emergency room, the patient had another witnessed syncopal episode. Telemetry showed a 63-s episode of sustained ventricular tachycardia at a rate of $240 \mathrm{bpm}$. She was given a bolus of $150 \mathrm{mg}$ of intravenous amiodarone. An electrocardiogram following this event was significant for sinus rhythm with frequent premature ventricular contractions and a prolonged QTc of $505 \mathrm{~ms}$. On physical exam, there were bibasilar crackles on auscultation of the lungs, jugular venous distention with positive hepatojugular reflex, +1 pitting lower leg edema, and normal S1, S2 heart sounds with no extra sounds or pericardial rub. Initial cardiac troponin was elevated at $0.11 \mathrm{ng} / \mathrm{mL}$ (normal range $0.00-0.08 \mathrm{ng} / \mathrm{mL}$ ), and her $\mathrm{N}$-terminal pro B-type natriuretic peptide was elevated at $812 \mathrm{pg} / \mathrm{mL}$ (normal range 0-100 pg/mL). Additional lab work that was completed is outlined in Table 1 and included mild anemia and normal kidney and liver functions. A 2-dimensional transthoracic echocardiogram (TTE) showed depressed left ventricular (LV) systolic function (ejection fraction of 40\%) with moderate global hypokinesis of the left ventricle, focal akinesis of mid inferior wall and mid septum, and trace pericardial effusion. Medical oncology, advanced heart failure, and cardiac electrophysiology services were consulted, and the patient was admitted to the cardiovascular progressive care unit. She was initiated on sotalol as treatment for ventricular arrythmia in addition to spironolactone, captopril, and intravenous furosemide for LV dysfunction. Chemotherapy was held given concerns of medication toxicity as the culprit of the presenting clinical situation. A cardiac magnetic resonance imaging with gadolinium was significant for edema (elevated T2 values), hyperemia, regional wall motion abnormalities, and mid myocardial late gadolinium enhancement involving the mid to distal septal, mid to distal inferior, and mid to distal anterior segments consistent with acute myocarditis. Repeat electrocardiogram was conducted after the patient had

\section{Karger'}




\section{Case Reports in Oncology}

Table 1. Blood test results for the patient at the time of admission

\begin{tabular}{l|l}
\hline Case Rep Oncol 2021;14:1853-1859 \\
\hline DOI: 10.1159/000520382 & $\begin{array}{l}\text { @ 2021 The Author(s). Published by S. Karger AG, Basel } \\
\text { www.karger.com/cro }\end{array}$ \\
\hline
\end{tabular}

Alali and Baljevic: Bortezomib-Induced Perimyocarditis

\begin{tabular}{|c|c|c|}
\hline \multirow{19}{*}{$\begin{array}{l}\text { Table 1. Blood test results for } \\
\text { the patient at the time of } \\
\text { admission }\end{array}$} & Test, unit & Value (reference range) \\
\hline & White blood cells, $\times 10 \mathrm{E}^{3} / \mu \mathrm{L}$ & $8.4(4.0-11.0)$ \\
\hline & Hemoglobin, g/dL & $10.1(11.0-15.1)$ \\
\hline & Platelet count, $\times 10 \mathrm{E}^{3} / \mu \mathrm{L}$ & $281(150-400)$ \\
\hline & Magnesium, mg/dL & $2.1(1.8-2.5)$ \\
\hline & Procalcitonin, ng/mL & $0.05(<0.10)$ \\
\hline & Lactic acid, mmol/L & $1.4(0.5-2.0)$ \\
\hline & D-dimer, ng/mL & $824(<500)$ \\
\hline & Glucose, mg/dL & $134(70-139)$ \\
\hline & Creatinine, mg/dL & $0.72(0.44-1.03)$ \\
\hline & Blood urea nitrogen, mg/dL & $12(6-20)$ \\
\hline & Sodium, mmol/L & $138(136-145)$ \\
\hline & Potassium, mmol/L & $3.4(3.5-5.1)$ \\
\hline & Albumin, g/dL & $3.4(3.5-5.1)$ \\
\hline & Calcium, mg/dL & $7.6(8.6-10.4)$ \\
\hline & Total bilirubin, $\mathrm{mg} / \mathrm{dL}$ & $0.4(0.3-1.0)$ \\
\hline & Alkaline phosphatase, $\mathrm{U} / \mathrm{L}$ & $51(32-91)$ \\
\hline & Aspartate transaminase, $\mathrm{U} / \mathrm{L}$ & $17(15-41)$ \\
\hline & Alanine transaminase, $\mathrm{U} / \mathrm{L}$ & $19(7-52)$ \\
\hline
\end{tabular}

recurrent pleuritic chest pain and showed sinus rhythm without any ST segments or T wave changes. Repeat TTE demonstrated that the pericardial effusion had increased in size, without evidence of tamponade physiology. She was started on colchicine for acute pericarditis. A right heart catheterization with endomyocardial biopsy was conducted to rule out giant cell myocarditis. After the biopsy, the patient had recurrent pleuritic chest pain. Repeat TTE showed further worsening of pericardial effusion now measuring $8 \mathrm{~mm}$ in its widest dimension (posteriorly) without evidence of cardiac tamponade. Ibuprofen was added with improvement in her chest pain. Subsequent TTE showed stabilization of her pericardial effusion. While awaiting the results of the endomyocardial biopsy, the patient was started on high-dose pulse steroid therapy with $1 \mathrm{~g}$ of intravenous methylprednisolone. Endomyocardial biopsy was negative for giant cell myocarditis, amyloidosis, or hemochromatosis, and methylprednisolone was discontinued. The biopsy showed nonspecific nondifferentiating findings of myocyte hypertrophy with areas of fibrosis and foci of fat. Infectious disease was consulted to evaluate any infectious cause of her acute perimyocarditis (shown in Table 2), which were not identified. Cumulatively, all tests were negative except for a positive myocardial polymerase chain reaction (PCR) for parvovirus B19 which was however negative on immunohistochemistry staining. Additionally, serologic parvovirus B19 IgM was negative, IgG was positive, and serum qualitative PCR was negative, indicating latent rather than acute parvovirus B19 infection, and parvovirus B19 was therefore deemed unlikely as the cause of her perimyocarditis. The close timing between treatment initiation with BTZ and patient presentation with acute perimyocarditis, in the absence of other causes, led the involved teams to conclude that her perimyocarditis was most likely a complication of BTZ therapy. The patient was discharged with a wearable external defibrillator (life-vest) and on sotalol, spironolactone, captopril, furosemide, colchicine, and ibuprofen. One week later, a repeat TTE showed resolution of her 


\section{Case Reports in Oncology}

Table 2. Infectious workup

\begin{tabular}{l|l}
\hline Case Rep Oncol 2021;14:1853-1859 \\
\hline DOI: 10.1159/000520382 & $\begin{array}{l}\text { @ 2021 The Author(s). Published by S. Karger AG, Basel } \\
\text { www.karger.com/cro }\end{array}$ \\
\hline
\end{tabular}

Alali and Baljevic: Bortezomib-Induced Perimyocarditis

\begin{tabular}{|c|c|}
\hline Test & Result \\
\hline Antinuclear antibody & Negative \\
\hline Double stranded DNA autoantibody & Negative \\
\hline Cardiolipin antibodies (IgM and IgG) & Negative \\
\hline Complements ( $\mathrm{C} 3$ and $\mathrm{C} 4$ ) & Normal \\
\hline Urine histoplasma antigen & Negative \\
\hline Serum histoplasma antigen & Negative \\
\hline Bartonella henselae antibody & Negative \\
\hline Adenovirus quantitative PCR & Negative \\
\hline Coxiella burnetii antibody (IgG) & Negative \\
\hline Trypanosoma cruzi antibody (IgG) & Negative \\
\hline Tuberculosis interferon antigen response & Negative \\
\hline Epstein-Barr virus quantitative PCR, blood & Negative \\
\hline Cytomegalovirus qualitative PCR, blood & Negative \\
\hline Toxoplasma PCR, blood & Negative \\
\hline $\begin{array}{l}\text { Enterovirus (including coxsackievirus) } \\
\text { RNA RT-PCR, blood }\end{array}$ & Negative \\
\hline Varicella-zoster virus PCR, blood & Negative \\
\hline Human-herpes-virus-6 PCR, blood & Negative \\
\hline Parvovirus B19 IgG & Positive \\
\hline Parvovirus B19 IgM & Negative \\
\hline Parvovirus qualitative PCR, blood & Negative \\
\hline Parvovirus B19 qualitative PCR on heart tissue & Positive \\
\hline Enterovirus RT-PCR on heart biopsy & Not detected \\
\hline $\begin{array}{l}\text { Immunoperoxidase stain for adenovirus } \\
\text { on heart biopsy }\end{array}$ & Negative \\
\hline $\begin{array}{l}\text { Immunoperoxidase stain for cytomegalovirus } \\
\text { on heart biopsy }\end{array}$ & Negative \\
\hline $\begin{array}{l}\text { Immunoperoxidase stain for parvovirus } \\
\text { on heart biopsy }\end{array}$ & Negative \\
\hline $\begin{array}{l}\text { In situ hybridization for Epstein-Barr virus } \\
\text { on heart biopsy }\end{array}$ & Negative \\
\hline Human-herpes-virus-6 PCR on heart biopsy & Negative \\
\hline
\end{tabular}

pericardial effusion with persistent LV dysfunction. At 2-month follow-up, her wearable external defibrillator was discontinued as there was no evidence of recurrence of her arrythmia on the loop recorder. At 6-month follow-up, a repeat cardiac MRI with late gadolinium enhancement showed scar formation in the distal inferior, distal septal, and mid anteroseptal segments but remained well controlled on goal-directed medical therapy and sotalol. She did not receive any additional doses of BTZ which was permanently discontinued. She eventually underwent autologous hematopoietic stem transplant for her MM, which was followed by uneventful lenalidomide-based maintenance therapy. 
Alali and Baljevic: Bortezomib-Induced Perimyocarditis

\section{Discussion}

The incidence of cardiotoxicity with the use of BTZ is reported between 0 and $17.9 \%$ [3]. Xiao et al. [4] reported the incidence of cardiotoxicity in a large meta-analysis at 3.8\%, whereas Laubach et al. [5] reported the incidence of congestive heart failure to be $2.0-7.6 \%$, the incidence of arrythmias 1.3-5.9\%, and the incidence of ischemic heart disease to be $1.2-2.9 \%$. Both meta-analyses failed to show an association of BTZ with adverse cardiac events. However, there continues to be case reports describing several cardiovascular toxicities related to BTZ use. Complete heart block [3], ventricular tachycardia and myocardial scarring [6, 7], heart failure with reduced ejection fraction and moderate pericardial effusion [8], fulminant myocarditis [9], and cardiac tamponade [10] have been described in several case reports.

The ubiquitin-proteosome system, under normal conditions, "tags" altered or misfolded intracellular proteins for degradation [2]. Its substrates include signaling molecules, cell cycle regulators, transcription factors, and antiapoptotic proteins [8]. In MM, the $26 \mathrm{~S}$ proteasome complex is hyperactive causing excessive intracellular removal of important proteins, such as tumor suppressor p53 and IкB (inhibitor of nuclear factor- $\kappa \mathrm{B}$ ). This results in the deregulation of cell cycle and apoptosis control leading to increased survival and proliferation of neoplastic clones [2]. Bortezomib, a dipeptidyl boronic acid, reversibly binds and inhibits the $20 \mathrm{~S}$ proteasome which is the proteolytic core particle of the 26S proteasome [3], therefore blocking the oncogenic progression of neoplastic cells by interfering with proteasome activity. However, the exact mechanism by which bortezomib interacts with the cardiac tissue is unknown.

Proteasome is important in protein hemostasis in the heart [2]. It helps maintain the normal size and shape of the heart by maintaining the protein quality in the myocytes, preserving the cellular mass, and controlling the quality of the sarcomeres [8]. Inhibition of proteasome activity results in the abnormal accumulation of misfolded proteins that associate with one another to form a higher order protein that is toxic to the cell and ultimately leads to apoptosis and cell death with release of cytokines activating the immune system and consequent inflammation $[8,11,12]$. This might explain how BTZ can lead to acute perimyocarditis.

This case demonstrates rare adverse cardiovascular effects of BTZ. Our patient presented with ventricular tachycardia resulting in syncope and was later diagnosed with acute perimyocarditis. To our knowledge, this is the first case to report of acute perimyocarditis secondary to BZT.

Our patient met the European Society of Cardiology's clinical diagnostic criteria for acute perimyocarditis (pleuritic chest pain, new pericardial effusion, syncope, ventricular tachycardia, elevated cardiac biomarkers, new left ventricular dysfunction on TTE, and cardiac MRI with late gadolinium enhancement) $[12,13]$. The pericardial effusion was present prior to the EMB but worsened after the procedure. Pericardial effusion is a rare complication after EMB [14], and it might have contributed to worsening pericardial effusion in this case. Based on the proximity between initiating treatment with BTZ and clinical presentation with acute perimyocarditis, together with the absence of other causative agents (including infectious) upon extensive testing, we concluded that the acute perimyocarditis is likely secondary to BTZ exposure.

It is worth mentioning that in our patient, the parvovirus B19 IgG level and myocardial PCR testing were positive. However, IgM serology, serum qualitative PCR for deoxyribonucleic acid, and immunohistochemical staining on myocardial tissue for parvovirus B19 were all negative. Given the lack of viral prodrome in our patient and the lack of evidence supporting an acute parvovirus B19 infection, the positive IgG serology and myocardial PCR

\section{Karger'}


for parvovirus B19 were thought to be indicative of latent persistence of the viral genome. Several studies in fact suggested that parvovirus DNA can persist in myocardial tissue after the prior primary infection, does not suggest a pathogenic role, and is not a proof of casual relationship between parvovirus infection and cardiac disease $[15,16]$.

To further evaluate the causality assessment of an adverse drug reaction to BTZ in our case, correlation was made using 2 separate causality assessment scoring tools: the World Health Organization - Uppsala Monitoring center (WHO-UMC) scale, which is a clinical judgment-based causality assessment tool [17], and the Naranjo algorithm [18]. Bortezomib association scored as "probable or likely" on the WHO-UMC and the Naranjo algorithm scored 6 points on a limited number of applicable questions, classifying association as "probable" (several algorithm questions could not be scored due to lack of applicability).

It is unclear whether lenalidomide might have potentiated this event as Fradley et al. [6] reported increased cardiovascular toxicity with combination of a proteasome inhibitor with immunomodulator drugs, but our patient was restarted on lenalidomide as a maintenance therapy after autologous hematopoietic stem transplant, with no recurrence or worsening in her cardiac function. Due to severity of the adverse drug reaction, BTZ was discontinued indefinitely. It is unclear if any patient-specific factors (genetic or otherwise) contributed to the likelihood of this event.

\section{Conclusion}

We describe a unique and - to our knowledge - the first case of acute perimyocarditis after BTZ therapy, as a rare and serious cardiac adverse event. This case illustrates that it can present with syncope and ventricular tachycardia, which further carry risks of patient morbidity and mortality. We recommend close clinical vigilance in patients receiving BTZ therapy and initiation of appropriate diagnostic and clinical cardiac monitoring for patients who may report cardiovascular symptoms. Last, all further BTZ use should be discontinued in such patients, and close monitoring employed, should the oncologic require further consideration of proteasome inhibitor-based therapy, as is usually the case in long-term management of MM and other hematologic malignancies.

\section{Statement of Ethics}

The article describes a case report. Therefore, no additional permission from our ethics committee was required. Written informed consent was obtained from the patient for publication of this case report and any accompanying images.

\section{Conflict of Interest Statement}

The authors have no conflicts of interest to declare.

\section{Funding Sources}

No funding was received.

\section{Karger ${ }^{\prime}=$}




\section{Case Reports in Oncology}

\begin{tabular}{l|l}
\hline Case Rep Oncol 2021;14:1853-1859 \\
\hline DOI: 10.1159/000520382 & $\begin{array}{l}\text { @ 2021 The Author(s). Published by S. Karger AG, Basel } \\
\text { www.karger.com/cro }\end{array}$ \\
\hline
\end{tabular}

Alali and Baljevic: Bortezomib-Induced Perimyocarditis

\section{Author Contributions}

Yaman Alali searched the literature and wrote the manuscript. Muhamed Baljevic supervised the patient treatment, critically revised, and edited the manuscript. All authors have made significant contributions to the manuscript and have reviewed it before submission. All authors have confirmed that the manuscript is not under consideration for review at any other journal. All authors have read and approved the final manuscript.

\section{Data Availability Statement}

All data underlying the results are available as part of the article, and no additional source data are required.

\section{References}

1 FDA. IBC velcade poilicy.

2 Giudice V, Vecchione C, Selleri C. Cardiotoxicity of novel targeted hematological therapies. Life. 2020;10(12): 344.

3 Diwadkar S, Patel AA, Fradley MG. Bortezomib-induced complete heart block and myocardial scar: the potential role of cardiac biomarkers in monitoring cardiotoxicity. Case Rep Cardiol. 2016;2016:3456287.

4 Xiao Y, Yin J, Wei J, Shang Z. Incidence and risk of cardiotoxicity associated with bortezomib in the treatment of cancer: a systematic review and meta-analysis. PLoS One. 2014;9(1):e87671.

5 Laubach JP, Moslehi JJ, Francis SA, San Miguel JF, Sonneveld P, Orlowski RZ, et al. A retrospective analysis of 3954 patients in phase $2 / 3$ trials of bortezomib for the treatment of multiple myeloma: towards providing a benchmark for the cardiac safety profile of proteasome inhibition in multiple myeloma. Br J Haematol. 2017; 178(4):547-60.

6 Fradley MG, Groarke JD, Laubach J, Alsina M, Lenihan DJ, Cornell RF, et al. Recurrent cardiotoxicity potentiated by the interaction of proteasome inhibitor and immunomodulatory therapy for the treatment of multiple myeloma. Br J Haematol. 2018;180(2):271-5.

7 Foley PW, Hamilton MS, Leyva F. Myocardial scarring following chemotherapy for multiple myeloma detected using late gadolinium hyperenhancement cardiovascular magnetic resonance. J Cardiovasc Med. 2010;11(5): 386-8.

8 Bockorny M, Chakravarty S, Schulman P, Bockorny B, Bona R. Severe heart failure after bortezomib treatment in a patient with multiple myeloma: a case report and review of the literature. Acta Haematol. 2012;128(4): 244-7.

9 Cheney A, Krieger E, Dardas T, Vincent L. From multiple myeloma to myocarditis. J Am Coll Cardiol. 2019;73(9 Suppl 1):2597.

10 Burkhart T, Keith MCL, Lenneman CAG, Fernando RR. Bortezomib-induced cardiac tamponade in a 49-year-old man. Tex Heart Inst J. 2018;45(4):260-3.

11 Wu P, Oren O, Gertz MA, Yang EH. Proteasome inhibitor-related cardiotoxicity: mechanisms, diagnosis, and management. Curr Oncol Rep. 2020;22:66-14.

12 Caforio ALP, Pankuweit S, Arbustini E, Basso C, Gimeno-Blanes J, Felix SB, et al. Current state of knowledge on aetiology, diagnosis, management, and therapy of myocarditis: a position statement of the European Society of Cardiology Working Group on Myocardial and Pericardial Diseases. Eur Heart J. 2013;34(33):2636-48.

13 Adler Y, Charron P, Imazio M, Badano L, Barón-Esquivias G, Bogaert J, et al. 2015 ESC Guidelines for the diagnosis and management of pericardial diseases. Kardiol Pol. 2015;73(11):1028-91.

14 Deckers JW, Hare JM, Baughman KL. Complications of transvenous right ventricular endomyocardial biopsy in adult patients with cardiomyopathy: a seven-year survey of 546 consecutive diagnostic procedures in a tertiary referral center. J Am Coll Cardiol. 1992;19(1):43-7.

15 Schenk T, Enders M, Pollak S, Hahn R, Huzly D. High prevalence of human parvovirus B19 DNA in myocardial autopsy samples from subjects without myocarditis or dilative cardiomyopathy. J Clin Microbiol. 2009;47(1): 106-10.

16 Koepsell SA, Anderson DR, Radio SJ. Parvovirus B19 is a bystander in adult myocarditis. Cardiovasc Pathol. 2012;21(6):476-81.

17 World Health Organization. The use of the WHO-UMC system for standardised case causality assessment. Available from: http://www.WHO-UMC.org/graphics/4409.pdf.

18 Naranjo CA, Busto U, Sellers EM, Sandor P, Ruiz I, Roberts EA, et al. A method for estimating the probability of adverse drug reactions. Clin Pharmacol Ther. 1981;30(2):239-45. 